\title{
Sudden Death NOS, CTCAE
}

National Cancer Institute

\section{Source}

National Cancer Institute. Sudden Death NOS, CT CAE. NCI Thesaurus. Code C143863.

An unexpected death that cannot be attributed to a CT CAE term associated with Grade 5 . 